University of Rhode Island

DigitalCommons@URI

Cancer Prevention Research Center Faculty

Publications

Cancer Prevention Research Center

2012

\title{
Cluster subtypes appropriate for preventing postpartum smoking relapse
}

\author{
Mary Colleen Simonelli \\ Wayne F. Velicer \\ University of Rhode Island, VELICER@URI.EDU
}

Follow this and additional works at: https://digitalcommons.uri.edu/cprc_facpubs

This is a pre-publication author manuscript of the final, published article.

Creative Commons License

(c) (i) $\Theta$

This work is licensed under a Creative Commons Attribution-Noncommercial-No Derivative Works 4.0 License.

\section{Citation/Publisher Attribution}

Simonelli, M. C., \& Velicer, W. F. (2012). Cluster subtypes appropriate for preventing postpartum smoking relapse. Addictive Behaviors, 37(3), 280-286. doi: 10.1016/j.addbeh.2011.11.001

Available at: https://doi.org/10.1016/j.addbeh.2011.11.001

This Article is brought to you for free and open access by the Cancer Prevention Research Center at DigitalCommons@URI. It has been accepted for inclusion in Cancer Prevention Research Center Faculty Publications by an authorized administrator of DigitalCommons@URI. For more information, please contact digitalcommons-group@uri.edu. 


\title{
Cluster Subtypes Appropriate for Preventing Postpartum Smoking Relapse
}

\author{
Mary Colleen Simonelli, RN, PhD and \\ William F Connell School of Nursing, Boston College \\ Wayne F Velicer, PhD \\ Cancer Prevention Research Center, University of Rhode Island
}

\begin{abstract}
Objective-While the majority of women quit smoking either before or during pregnancy, 60 to $80 \%$ relapse in the postpartum period. The objective of this research was to examine postpartum women who quit smoking during their pregnancies and to determine the predictive factors for relapse in the postpartum period by identifying different subgroups that predict risk of relapse.
\end{abstract}

Method-One hundred forty four postpartum women who were abstinent at the time of delivery were recruited. Data regarding the Acquisition Stage of Change, Decisional Balance and Situational Temptations to Smoke were assessed in the immediate postpartum period. Based on their intention to remain abstinent, 121 women identified in the acquisition-Precontemplation (aPC) group comprised the study sample. Smoking status was assessed again at 2-months postpartum

Results-A cluster analysis was performed to idenitfy subgroups of the acquisitionPrecontemplation (aPC) group. Four subgroups were identified and were labeled Most Protected, Ambivalent, Risk Denial, and High Risk. Logistic regression was performed to establish external validity of the clusters. The clusters and exclusive breastfeeding were the only statistically significant variables associated with relapse at 2-months postpartum.

Conclusions-The results confirmed the clusters identified in previous prevention research with both adolescents and postpartum women, The cluster profiles can serve to guide the development of a tailored intervention program.

\section{Keywords}

Transtheoretical Model; Smoking; Relapse; Pregnancy; Postpartum; Cluster analysis

It is universally accepted that cigarette smoking is the single most preventable risk factor for death and disease (United States Department of Health and Human Services, 2010).. The additional risk factors associated with smoking for childbearing women call for a greater focus in this area. While the majority of women quit either prior to or during pregnancy, the relapse rates are 60 to $80 \%$ in the postpartum period (McBride, Curry, Lando, Pirie, Nelson,

(C) 2011 Elsevier Ltd. All rights reserved.

Corresponding Author: Mary Colleen Simonelli, William F Connell School of Nursing, 140 Commonwealth Ave, Boston College, Chestnut Hill, MA 02467, colleen.simonelli@ bc.edu, Tel: 617-552-4926; fax: 617-552-0745.

Publisher's Disclaimer: This is a PDF file of an unedited manuscript that has been accepted for publication. As a service to our customers we are providing this early version of the manuscript. The manuscript will undergo copyediting, typesetting, and review of the resulting proof before it is published in its final citable form. Please note that during the production process errors may be discovered which could affect the content, and all legal disclaimers that apply to the journal pertain. 
\& Grothaus, 1999; Stotts, DiClemente, Carbonari, \& Mullen, 2000). A return to smoking has an impact not only on a woman's health but also on her infant and family (Marble, 1996; Schoenborn, Vickerie, \& Barnes, 2003). The period of cessation is typically 6 to 12 months (USDHHS, 2000). This suggests that the problem should not be viewed from the typical relapse model but rather from a prevention perspective. The purpose of this study was to examine postpartum women who quit smoking during their pregnancies from a prevention perspective and determine the predictive factors for relapse in the postpartum period

\section{Cessation and Relapse during Pregnancy}

Pregnancy, considered the "golden opportunity" for cessation, is associated with a marked increase in quit attempts. Approximately $26 \%$ of pregnant women are current smokers (Coleman \& Joyce, 2003). Studies have claimed as high as $40-50 \%$ self-reported cessation rates during pregnancy with the use of various interventions (Coleman \& Joyce; Fingerhut, Kleinman, \& Kendrick, 1990; Kahn, Certain, \& Whitaker, 2002; Walsh, Redman, Brinsmead, Byrne, \& Melmeth, 1997). These have included self-help programs, telephone and face-to-face counseling, support groups, newsletters, kits and booklets. Unfortunately the $60-80 \%$ relapse rate occurs regardless of the cessation interventions employed (Fingerhut et al., 1990; McBride et al., 1999; Stotts, et al., 2000). One consistently strong predictor of continued smoking and/or relapse, in pregnancy-related smoking cessation, is being partnered with a smoker (Gulliver, Hughes, Solomon, \& Dey, 1995; Hakansson, Lendhals, \& Petersson, 1999; McBride et al., 1999; Woodby, Windsor, Snyder, Kohler, \& DiClemente, 1999; Ziebland \& Fuller, 2001). Mullen (2004) synthesized the findings from the intervention trials, predictor studies and qualitative work undertaken between 1985 and 2003. Her review confirmed the need for examination of this transition from pregnancy to postpartum in relation to smoking relapse. Mullen made specific recommendations for future research, including attending to partner smoking status and support, research involving low socioeconomic status women, development of a standard for cessation, exploration of intrinsic and extrinsic motivators, and use of staging criteria for postpartum smoking prediction rather than relapse prevention alone.

\section{Transtheoretical Model}

The Transtheoretical Model (TTM) is one of the most widely used models of behavior change. One application involves tailoring messages to the individual, which has proved very effective in smoking cessation, increasing exercise, improving diet, decreasing UV exposure, and increasing adherence to mammography use in general populations (Greene, et al, 1998; Hollis, et al, 2005; Prochaska, DiClemente, Velicer, \& Rossi, 1993; Prochaska, et al, 2001a; Prochaska, et al, 2001b; Prochaska, et al, 2004, Rakowski, et al, 1998; Velicer \& Prochaska, 1999; Velicer, et al, 1999; Velicer, Prochaska, \& Redding, 2006). Stage of change is the central organizing construct of the model. Stage of change represents the temporal or evolutionary dimension integrating current behavior and intention to engage in the new health behavior (Prochaska et al., 2005; Velicer, Prochaska, Fava, Rossi, Redding, $\&$ Laforge, 2000). The five stages are Precontemplation - the person has no intention to change behavior in the foreseeable future, Contemplation - the person is aware that a problem exists but has not yet made a commitment to change behavior, Preparation - the person is intending to take action in the next 30 days and has made an attempt to change behavior in past year, Action - the person is involved in overt behavior change, and Maintenance - the person has been successful in behavior change for six months and is actively working to prevent relapse. The other dimensions of the model are the independent variable dimension, including the processes of change, and the intermediate variable dimension, which includes the decisional balance, and situational temptations. Tailored interventions can use a sequential approach, providing feedback based on the TTM variables, typically in order of largest effect size, or simultaneously (Velicer et al., 1993; 
Velicer, Prochaska, \& Redding, 2006). In the simultaneous case, the feedback is based on the profile of the individual across different TTM variables (Levesque, Driskell, \& Prochaska,2008).

For smoking cessation, a series of cluster analysis studies starting with Velicer et al (1995) have found consistent subtypes within each stage of change. The subtypes have been replicated across multiple samples for smoking cessation (Anatchkova, et al, 2005, 2006a, 2006b, Dijkstra, Bakker, \& de Vries, 1997; Kremers, Mudde, \& de Vries, 2001, Norman, Velicer, Fava, \& Prochaska, 2000). Recently the same typology has also been replicated with other behaviors (Santiago Rivas et al, 2010Santiago Rivas et al, 2011 a , 2011b).

\section{Prevention Subtypes}

The model has also been applied to the development of prevention programs for smoking, alcohol use, and other behaviors. Parallel to the stages of change for cessation, a staging algorithm has been developed for prevention, called the Acquisition Stages of Change. Three Stages of smoking Acquisition (Pallonen et al., 1998) have been identified: Acquisition Precontemplation (aPC) -the person has no intention of acquiring this behavior, Acquisition Contemplation $(\mathrm{aC})$ - the person is considering acquiring this behavior but not within the next six months, and Acquisition Preparation (aPR)- the person intends to acquire the behavior in the next 30 days. Other researchers have employed the same or similar stage of acquisition idea (Aveyard, Lancashire, Almond, \& Cheng, 2002; Otake \& Shimai, 2002; Kremers de Vries, Mudde, \&Candel, 2004), including the susceptibility concept of Pierce and colleagues (Unger, Johnson, Stoddard, Nezami, \&Chou, 1997; Pierce JP, Choi, Gilpin, Farkas, \& Merritt, 1996).

School-based smoking prevention programs are typically identical for all students. Tailoring prevention materials to focus on individual needs with an emphasis on students at highest risk is a promising alternative. Recent prevention programs have tailored materials based on the Stages of Acquisition, an extension of the Stages of Change used to tailor smoking cessation materials effectively for adults However, about $90 \%$ of nonsmoking adolescents classify themselves in the aPC stage, which limited the degree of tailoring that could be done. The interventions have resulted in only minor gains (Hollis, Polen, Whitlock, Lichtenstein, Mullooly, Velicer, \& Redding, 2005).).

Velicer et al (2008) performed a cluster analysis within the acquisition Precontemplation group, using the Decisional Balance and Situational Temptations scales, for three random subsamples of adolescents within the aPC stage $\left(\mathrm{N}_{1}=\mathrm{N}_{2}=\mathrm{N}_{3}=514\right)$. Four distinct subtypes were identified in each subsample: High Risk, Most Protected, Ambivalent, and Risk Denial. External validity was established using family support for nonsmoking, peer variables, and stage classification at follow-up assessment (12, 24, and 36 Months). Family support for nonsmoking was related to subtype much more strongly than peer interactions. Subjects in the Most Protected subgroup were the most likely to remain in the aPC stage at each follow-up assessment. Velicer, et al, (2009) replicated the same four types for both smoking and alcohol in five subsamples of middle school students. Subtype membership, along with membership in the $\mathrm{aC}$ and $\mathrm{aPR}$ stages, provides important additional information for tailoring smoking prevention materials. Tailored interventions can focus on those adolescents at highest risk and limit or avoid expending resources on those at very low risk.

Most recently Thyrian, Hannover, Roske, Rumpf, John and Hapke (2006) replicated the four subtypes within the acquisition Precontemplation stage among ex-smoking postpartum women. During the study 1,128 women identified as smokers at the beginning of pregnancy. The sample included the 317 women who claimed to have quit during pregnancy and were smoke free at the time of delivery. Examining the self-efficacy, pros and cons of remaining a 
nonsmoker, Thyrian et al. identified the 4-cluster solution as most interpretable. A logistic regression was performed to identify variables that would predict smoking status at 12 months postpartum. Cluster assignment was predictive of smoking status, whereas partner smoking status, age, education, breastfeeding and treatment group assignment were not significant. Members of the "high-risk group" were 5.77 times $(p<.01)$, "risk-denial group" were 5.01 times $(p<.01)$, and the "ambivalent group" were 3.26 times $(p<.01)$ more likely to return to smoking at the 12-month follow up than those in the "most protected" group.

\section{Study Overview}

Utilizing the TTM as a conceptual framework, the purpose of this prospective longitudinal survey research was to examine the stage of change, decisional balance and temptation to smoke among postpartum women who quit prior to or during their pregnancy. A cluster analysis of the postpartum women, who claimed an intention to remain abstinent postpartum, was conducted to identify subgroups of this sample that could benefit from different tailored interventions for relapse prevention. Data from two months after the baseline assessment was employed to provide initial external validity. The information gained from this study may lead to development of a tailored intervention program to improve rates of continuous abstinence for postpartum women.

\section{Method}

\section{Sample}

Eligible women were of any race, age, ethnicity, and marital status, in the immediate postpartum period (defined as the first week following delivery), had a history of smoking, claimed to have quit smoking within the past twelve months, and spoke English. The project received full approval from the hospital's human research committee and the institutional review board of the university where the principal investigator was enrolled. Over the eighteen months of recruitment, 144 women gave informed consent and were enrolled in the study; 23 of these women claimed an intention to return to smoking and were consequently excluded from further analysis. This study focused on the subsample of 121 women who classified themselves as being in the (aPC) stage; those with an intention to remain abstinent from smoking postpartum. The sample is described in greater detail in Table 1.

For the second assessment, participants were asked to complete questionnaires and to return them in a pre-addressed stamped envelope provided. Participants who did not complete and return the surveys were given the option of completing via email or telephone survey with the research staff. Of the 121 (ac-PC) participants originally enrolled $77(63.7 \%)$ returned the completed surveys via mail, $34(28.1 \%)$ via telephone, 2 (1.6\%) via e-mail and $8(6.6 \%)$ were lost to follow-up.

\section{Procedure}

Participants were asked to complete questionnaires during the postpartum hospital stay and again at two months postpartum. Recruitment of participants was conducted from November 2005 until May 2007 at the obstetrical services of two major teaching hospitals in the Northeast region of the United States. Women were screened by study staff during their immediate postpartum stay.

Women were asked about their smoking status during the past 12 months and their willingness to participate in the study. Women who self-identified as smokers and indicated that they had quit smoking within twelve months of their delivery, and gave informed consent were enrolled in the study. Participating women were then mailed follow-up surveys approximately eight weeks after delivery. 


\section{Measures}

Sociodemographic Measures-Sociodemographic information included, age, race/ ethnic group, educational attainment, socioeconomic status, marital status, obstetrical history (number of pregnancies, including number of children currently living with the participant), and smoking history (e.g., age at onset, pack/year history, smoking status of social network, number of previous quit attempts, and house smoking rules). Information on infant feeding status (breastfeeding, bottle-feeding or combination), general health of women and their infants, and sleep pattern was also collected.

Stages of Change Measure-The staging algorithm for acquisition was employed. Participants were classified as acquisition-precontemplators (aPC) if they claimed no intention to return to smoking; acquisition-contemplators $(\mathrm{aC})$ if they claimed they were uncertain but wished to remain nonsmokers for six months; and acquisition-preparers (aPR) if they planned to return to smoking in the next 30 days.

Perceived Partner Support for Not Smoking-The scale asked participants to rate how often their partner discussed or provided positive support for their cessation efforts. The measure was a four-item five-point Likert scale questionnaire adapted from the adolescent smoking acquisition studies (Redding et al., 1998; Redding et al., 1999).

Decisional Balance Inventory-The Decisional Balance Inventory (Velicer et al., 1985) is a 12-item scale using a five-point Likert rating of 1 (not important) to 5 (extremely important) measure of the importance of reasons and concerns relating to smoking. It is based on the Janis and Mann model (1977) and produces two subscales, the Pros of Smoking and the Cons of Smoking.

In this study the reliability analysis of the Decisional Balance Inventory had higher Coefficient Alphas when one item was deleted from both the Pros and Cons. "My family and friends like me better when I'm happily smoking than when I am miserably trying to quit," and "I'm embarrassed to have to smoke," were the deleted items. Cronbach's alphas for the remaining items were .74 (pros) and .74 (cons).

Situational Temptations Inventory-The Situation al Temptations Inventory (Velicer et al, 1990) consists of 18 items in a five-point Likert format from 1 (not at all tempted) to 5 (extremely tempted) and assesses the participant's level of temptation to smoke in various situations. Previous studies have reported that all forms of this scale have demonstrated fair to excellent internal reliability with Cronbach's alphas between .68 and .92 as well as construct and predictive validity (Velicer et al., 1990; Pallonen et al., 1998; Plummer et al., 2001). For this sample the Cronbach's Alpha was .93 for the 18 items analyzed.

\section{Cluster Analysis}

Variables are routinely standardized to a comparable metric prior to clustering to equalize the contribution of each variable to the outcome of each study (Aldenderfer \& Blasfield, 1984). For our study, all the variables to be included in cluster identification procedures (Decisional Balance -Pros and Cons-, and Self efficacy) were standardized to $T$ - scores ( $M=$ $50, S D=10)$. This procedure has been used in comparable cluster analysis studies (Anatchkova, et al., 2005, 2006a, 2006b; Norman et al., 2000; Velicer et al., 1995).

Similarity measures have been developed to estimate the similarity or proximities, between the individuals. The most commonly used is the squared Euclidean distance (Everitt, Landau, \& Leese, 2001) which was employed in this study. The squared Euclidean distance metric was calculated on the three standardized variables: Pros, Cons, and Self-efficacy. 
Ward's minimum variance method (Ward, 1963) was employed to form the clusters. Several indices were used to determine the number of clusters: the cubic clustering criterion (CCC), the pseudo $F$ test (Calinski \& Harabasz, 1974), and the pseudo $t^{2}$ test. Values of the CCC greater than 2 or 3 indicate good clusters. A local peak, followed by a drop in the value of the CCC, indicates an appropriate number of clusters for the data (SAS Institute Inc., 1999). The pseudo $F$ statistics, where large values indicate a stopping point, and the pseudo $t^{2}$ were also used. Following the results from the three indices, visual inspection of the cluster profiles was also performed with a focus on the shape (configuration of the scores; pattern of dip and rises), level (the mean score of the case over all the variables), and scatter (the standard deviation or dispersion of the scores) of the profiles. In this sample the four cluster solution was the most interpretable when compared with the three and five cluster solutions in scatter and shape. In previous studies where multiple subgroups were available, the three and five cluster solutions did not replicate across samples (Velicer, et al., 2007; Velicer et al, 2009). It is graphically depicted in Figure 1. (Cluster labeling belowreflected the labels used in previous studies.)

\section{Results}

In this study, the first cluster was labeled Ambivalent and included 36 (29.75\%) of the women. The profile was relatively flat with pros, cons and temptations close to the mean of 50 .

The second cluster was labeled High Risk and included 25 (20.66\%) of the women. The profile was characterized by a "V shape" with high temptations to smoke (more than $1 \mathrm{SD}$ above the mean), high pros (almost $1 \mathrm{SD}$ above the mean) and average cons.

The third cluster was labeled Most Protected and included 36 (29.75\%) of the women. The profile was characterized by an "inverted V" shape with low temptations to smoke (more than $1 \mathrm{SD}$ below the mean), low pros (about $1 \mathrm{SD}$ below the mean) and cons close to the mean.

The fourth cluster was labeled Risk Denial and included 24 (19.84\%) of the women. The profile was also a "V" shape with average temptations, higher than average pros (almost 1 $\mathrm{SD}$ above the mean) and lower than average cons (1 SD below the mean).

\section{External Validity}

A logistic regression was performed to establish external validity for the cluster solutions using smoking status at the two month time point as the outcome variable. The forced entry method was employed for building the regression model. The cluster variables as well as variables not utilized in development of the clusters, but with a theoretical significance to the outcome variable, were entered as the independent variables. The four clusters ("protected" as the reference), as well as variables consistently associated with relapse; partner smoking status (nonsmoker as the reference), education (> high school graduate as the reference), and breastfeeding (bottle feeding as reference) were evaluated. The logistic regression shown in Table 3 examined the 4-cluster solution, age, partner smoking status, education, and exclusive breastfeeding. Only the clusters and exclusive breastfeeding were statistically significant in this model. Cluster membership more than doubled the odds of relapse for the "high risk", "risk denial" and "ambivalent" groups $(O R>2.6$; "most protected" cluster as the reference category). Exclusive breastfeeding, showed a negative relationship to relapse reducing the odds of relapse by more than half $(p<.05)$. At the $2-$ month assessment $35 \%$ of the sample had relapsed to smoking. Current smoking status evaluated in its association with the individual's cluster prediction revealed that approximately $50 \%$ of the participants in the "high risk cluster" resumed smoking by two 
months postpartum. The "ambivalent" and "risk denial" participants relapsed at a rate of $40 \%$ while only $20 \%$ of those in the "most protected cluster' had resumed smoking at the two-month assessment. There was a significant difference in the likelihood of resuming smoking at 2-months postpartum. Members of the most protected cluster were less likely to resume smoking than members of the other three clusters $\left(\chi^{2}=4.67, d f=1, p<.05\right)$.

\section{Discussion}

The constructs of the TTM - decisional balance (pros and cons of smoking) and temptations to smoke- were successfully utilized to identify subtypes or clusters within the aPC stage of change. Additionally various levels of risk were predicted based on an individual's cluster membership. Predictions based on the TTM constructs were statistically supported at the 2month follow-up with members of the "most protected" cluster remaining nonsmokers when compared with members of the ambivalent," "risk denial" and "high risk" clusters.

The cluster analysis presented here replicates those obtained in previous studies examining adolescent acquisition (Velicer et al, 2008, 2009), and German postpartum reacquisition (Thyrian et al., 2006). With unique populations such as adolescents who have not yet started to smoke and postpartum women who have quit for pregnancy, subdivision of the acquisition-precontemplation stage has revealed some distinct differences on which tailored interventions may be applied (Dijkstra, Bakker, \& de Vries, 1997; Kremers, Mudde, \& de Vries, 2001; Norman, Velicer, Fava, \& Prochaska, 2000; Pallonen, Prochaska, Velicer, Prokhorov, \& Smith, 1998; Velicer et al., in press). In these very different populations, the same four clusters have been identified within aPC stage. This provides potential avenues for intervention work.

\section{Utility of Clusters}

Everitt, Landau, and Leese (2001) provide a description of the many reasons for developing a classification system and provide numerous examples from different branches of science. Of particular interest in the area of health promotion is that the identification of cluster subtypes has the potential to guide the development of tailored interventions for the promotion of sun protection habits. Tailored interventions have typically been based on or developed by employing a series of variables identified as critical to success and then using those variables sequentially to subdivide the sample (Velicer et al, 1993; Velicer \& Prochaska, 1999). An alternative method is to use the cluster subgroups as the basis for tailoring and assign individuals to groups based on their distance from each of the subgroups (for an example of this approach, see Levesque, et al.,2008). There is no evidence suggesting which approach is the most effective.

\section{Cluster Analysis: The Importance of Replication}

Replication is critical for any cluster analysis study since the cluster analysis is an exploratory method that will always produce clusters. If there are no natural clusters, the methods results in 'dissection' (Everitt, Landau, \& Leese, 2001). If natural clusters exist, they should demonstrate internal cohesion (homogeneity) and external isolation (separation). Replication provides critical evidence that the correct number of clusters has been selected and can help guide the interpretation of the clusters. The present exploratory analysis could not be divdied into subgroups because of the limited sample size. However, if the results of this study are placed in the context of the other smoking prevention studies that have investigated subgroups within ac-PC stage, the results are impressive. The same four clusters have been found and replicated repeatedly. Velicer et al (2008) first reported these clusters for smoking cessation with adolescents with multiple replications reported within that study. The cluster membership was predictive of future acquisition. The same clusters 
were found in a large adolescent aPC sample for both smoking acquisition and alcohol acquisition and replicated in five subsamples for both (Velicer, et al, 2009). The same analysis was first performed within a postpartum sample in Germany and the same four clusters were found there (Thyrian, et al, 2006)). We consider this cross sample, cross culture, and cross behavior replication to represent a real strength of this study.

\section{Designing Interventions based on Clusters}

The prevention subtypes provide information about the chance of relapse for the participants. Abstinence rates may be strengthened by tailoring interventions to the characteristics of the individuals within a specific cluster. Members of the Most Protected cluster perceived the cons of smoking as high, the pros of smoking as low and did not feel tempted to smoke in many situations. Interventions with these women could be minimal; a clinician working with a "most protected" client would simply provide support for her current behavior.

Conversely women in the High Risk cluster are very strongly tempted in different situations, perceive many advantages and only some disadvantages of smoking. A clinician must focus on the following interventions with these women, highlighting tempting situations for the client, developing strategies for avoiding tempting situations, and overall strengthening of the client's self-efficacy to remain a nonsmoker since this group is at greatest risk for relapse.

Women in the Ambivalent Cluster perceive only moderate disadvantages to smoking but also see only moderate advantages, as well as average temptations, to smoking. Interventions with these women could include a general discussion of smoking versus nonsmoking and reinforcement of cessation rather than resumption of their "suspended" behavior.

Women in the Risk denial cluster have a very low perception of the disadvantages of smoking. Members of this group also have moderate temptations and perceive average advantages of smoking. Interventions with this cluster need to include heightened awareness of the cons of smoking. Clinicians need to discuss the continued disadvantages of smoking above and beyond pregnancy complications, particularly the hazards of environmental tobacco smoke exposure to their infants and families..

\section{Limitations}

The major limitation of this research is sample size. Although it was determined that a minimum of 120 participants would be necessary, based on the estimate derived from the formula to yield an $80 \%$ chance of detecting a 5\% difference in the characteristics of those that comprise the various stages of change, frequency of the various TTM stages varied greatly, resulting in highly disproportionate categories. Of the 144 participants recruited 121 fell into the acquisition-precontemplation stage (ac-PC), 22 in the acquisition-contemplation stage (ac-C), and only 1 was acquisition-preparation (ac-P). Consequently mean comparisons of these groups were not possible.

As this research was longitudinal, retention is another important factor. Of the 144 women who originally consented and participated in the baseline survey $131(91 \%)$ returned the 2month follow-up survey. As further analysis was conducted with the subsample of the 121 acquisition-precontemplators retention of these participants must be considered. Eight of the 121 that identified themselves in ac-PC were lost to follow-up; this represented a $6.6 \%$ attrition rate in the sample. While overall less than a $10 \%$ loss of participants is considered adequate for data analysis, this decrease given the smaller original sample size may have played a role in the lack of differentiation on some variables. Additionally the follow-up was 
conducted at 2-months postpartum at this point only $35 \%$ of the total sample had relapsed; follow-up at 6 or 12-months postpartum may have replicated previous research more closely as these are the timeframes used more consistently in the literature (McBride et al., 1999; Stotts et al., 2000; Thyrian et al., 2006; Woodby et al., 1998).

The use of self-report for smoking status rather than biochemical marker validation may be considered a limitation of this study. However participants were asked multiple questions including; "Have you taken even a puff of a cigarette since the birth of your baby?", to determine smoking status. Previous research has found this to an accurate measure for smoking cessation (Velicer, Prochaska, Rossi, \& Snow, 1992).

Generalizability of the sample may also be a limitation. Participants were recruited almost entirely from a single postpartum unit in a major metropolitan city in the Northeast. The majority of the sample was white, and had a higher level of educational attainment than other samples in the literature as well as the broader US population of postpartum women with a history of quitting smoking during their pregnancy (USDHHS, 2000). However consistency between some aspects of these findings and Thyrian et al.'s (2006) work in Germany argues that the role of the cluster variables may generalize to this broader population of US women. While Thyrian et al.'s sample was also a predominantly white sample; his participants varied more in education than those in this study sample.

\section{Conclusions}

Intervention work stemming from the use of prevention subtypes confirmed in this study may strengthen abstinence rates. Implications of the cluster membership include the ability to tailor interventions to the individual which has been found to be more effective in preventing relapse than standard interventions. Overall the predictive value of the clusters suggests avenues for interventions. Tailoring information based on the clusters may present an effective tool for improved smoking cessation among postpartum women.

\section{Acknowledgments}

Grant DA020112 from the National Institute for Drug Abuse partially supported this research.

\section{References}

Anatchkova MD, Velicer WF, Prochaska JO. Replication of subtypes for smoking cessation with the contemplation stage of change. Addictive Behaviors. 2005; 30:915-927. [PubMed: 15893089]

Anatchkova MD, Velicer WF, Prochaska JO. Replication of subtypes for smoking cessation with the Preparation stage of change. Addictive Behaviors. 2006a; 31:359-366. [PubMed: 15967587]

Anatchkova MD, Velicer WF, Prochaska JO. Replication of subtypes for smoking cessation with the Precontemplation stage of change. Addictive Behaviors. 2006b; 31:1101-1115. [PubMed: 16139436]

Coleman G, Joyce T. Trends in smoking before, during and after pregnancy in ten states. American Journal of Preventive Medicine. 2003; 24(1):29-35. [PubMed: 12554021]

Dijkstra, A.; Bakker, M.; deVries, H. Subtypes within a sample of precontemplating smokers: A preliminary extension of the stages of change. 1997.

Ershoff D, Quinn V, Mullen P. Relapse prevention among women who stop smoking early in pregnancy: A randomized clinical trial of a self-help intervention. American Journal of Preventive Medicine. 1995; 11:178-184. [PubMed: 7662397]

Everitt, B.; Landau, S.; Leese, M. Cluster analysis. 4. New York: Oxford University Press Inc; 2001.

Fava J, Velicer W, Prochaska J. Applying the Transtheoretical Model to a representative sample of smokers. Addictive Behaviors. 1995; 20(2):189-203. [PubMed: 7484313]

Addict Behav. Author manuscript; available in PMC 2013 March 1. 
Fingerhut L, Kleinman J, Kendrick J. Smoking before, during, and after pregnancy. American Journal of Public Health. 1990; 80(5):541-544. [PubMed: 2327529]

Greene GW, Rossi SR, Rossi JS, Fava JL, Prochaska JO, Velicer WF. An expert system intervention for dietary fat reduction. Annals of Behavioral Medicine. 1998; 20(supplement):S197.

Gulliver SB, Hughes JR, Solomon LJ, Dey AN. An investigation of self-efficacy, partner support and daily stresses as predictors of relapse to smokers in self-quitters. Addiction. 1995; 90:767-772. [PubMed: 7633293]

Hakansson A, Lendhals L, Petersson C. Which women stop smoking? Acta Obstetrica et Gynecologica Scandinavica. 1999; 78:217-224.

Humphreys K, Rosenheck R. Sequential validation of cluster analytic subtypes of homeless veterans. American Journal of Community Psychology. 1995; 23(1):75-97.

Hollis JF, Polen MR, Whitlock EP, Lichtenstein E, Mullooly JP, Velicer WF, Redding CA. TEEN REACH: Outcomes from a randomized controlled trial of a tobacco reduction program among teens seen in primary medical care. Pediatrics. 2005; 115:981-999. [PubMed: 15805374]

Kahn RS, Certain L, Whitaker RC. A reexamination of smoking before, during, and after pregnancy. American Journal of Public Health. 2002; 92(11):1801-1808. [PubMed: 12406812]

Kremers S, Mudde A, deVries H. Subtypes within the precontemplation stage of adolescent smoking acquisition. Addictive Behaviors. 2001; 26:237-251. [PubMed: 11316379]

Levesque DA, Driskell MM, Prochaska JM. Acceptability of a stage-matched expert system intervention for domestic violence offenders. Violence and Victims. 2008; 23:432-445. [PubMed: 18788337]

MacLean L, Estable A, Sims-Jones N, Edwards N. Concurrent transitions in smoking status and maternal role. Journal of Nursing Scholarship. 2002; 34(1):39-40.

McBride CM, Curry SJ, Lando HA, Pirie PL, Nelson JC, Grothaus LC. Prevention of relapse in women who quit during pregnancy. American Journal of Public Health. 1999; 89(5):706-711. [PubMed: 10224982]

Mullen P. How can more smoking suspension during pregnancy become lifelong abstinence? Lessons learned about predictors, interventions, and gaps in our accumulated knowledge. Nicotine \& Tobacco Research. 2004; 6(supp2):S217-s238. [PubMed: 15203823]

Norman G, Velicer W, Fava J, Prochaska J. Cluster subtypes within stage of change in a representative sample of smokers. Addictive Behaviors. 2000; 25(2):183-204. [PubMed: 10795944]

Pallonen U, Prochaska J, Velicer W, Prokhorov A, Smith N. Stages of acquisition and cessation for adolescent smoking: An empirical integration. Addictive Behaviors. 1998; 23(3):303-324. [PubMed: 9668929]

Pasquale PB. Pregnancy and smoking: The unrecognized addiction. Journal of Perinatal Education. 1993; 2(2):15-20.

Plummer B, Velicer W, Redding C, Prochaska J, Rossi J, Pallonen U, Meier K. Stage of change, decisional balance, and temptations for smoking: Measurement and validation in a large, schoolbased population of adolescents. Addictive Behaviors. 2001; 26:551-571. [PubMed: 11456077]

Pomerleau C, Namenek Brouwer R, Jones L. Weight concerns in women smokers during pregnancy and postpartum. Addictive Behaviors. 2000; 25(5):759-67. [PubMed: 11023016]

Prochaska JO, DiClemente CC, Velicer WF, Rossi JS. Standardized, individualized, interactive and personalized self-help programs for smoking cessation. Health Psychology. 1993; 12(5):399-405. [PubMed: 8223364]

Prochaska J, Velicer W, DiClemente C, Fava J. Measuring processes of change: Applications to the cessation of smoking. Journal of Consulting and Clinical Psychology. 1988; 56(4):520-528. [PubMed: 3198809]

Prochaska JO, Velicer WF, Fava JL, Ruggiero L, Laforge RG, Rossi JS, Johnson SS, Lee PA. Counselor and stimulus control enhancements of a stage-matched expert system intervention for smokers in a managed care setting. Preventive Medicine. 2001; 32:23-32. [PubMed: 11162323]

Prochaska JO, Velicer WF, Fava JL, Rossi JS, Tsoh JY. Evaluating a Population-based Recruitment Approach and a Stage-based Expert System Intervention for Smoking Cessation. Addictive Behaviors. 2001; 26:583-602. [PubMed: 11456079] 
Prochaska JO, Velicer WF, Rossi JS, Redding CA, Greene GW, Rossi SR, Sun X, Fava JL, Laforge R, Plummer BA. Multiple Risk Expert System Interventions: Impact of Simultaneous Stage-matched Expert System Interventions for Smoking, High Fat Diet and Sun Exposure in a Population of Parents. Health Psychology. 2004a; 23:503-516. [PubMed: 15367070]

Rakowski W, Ehrich B, Goldstein MG, Rimer BK, Pearlman DN, Clark MA, Velicer WF, Woolverton H. Increasing mammography among women aged $40-74$ by use of a stage-matched, tailored intervention. Preventive Medicine. 1998; 27:748-756. [PubMed: 9808807]

Redding, CA.; Velicer, WF.; Evers, KE.; Prochaska, JO. Preventing Postpartum Relapse: Some New Approaches to Meeting the Challenge. In: Hannöver, W.; Röske, K.; Thryian, JR., editors. Smoking Cessation and Relapse Prevention in Women Post Partum. Lengerich; Pabst: 2007. p. 96-112.

Ruggiero L, Rossi J, Prochaska J, Glasgow R, DeGroot M, Dryfoos J, et al. Smoking and diabetes: Readiness for change and provider advice. Addictive Behaviors. 1999; 24(4):573-578. [PubMed: 10466853]

Santiago Rivas M, Velicer WF, Redding CA, Prochaska JO, Paiva AL. Cluster Subtypes within the Preparation Stage of Change for Sun Protection Behavior. Applied Psychology: Health and Well Being. 2010; 00:00-00.

Santiago Rivas M, Velicer WF, Redding CA, Prochaska JO, Paiva AL. Cluster Subtypes within the Precontemplation Stage of Change for Sun Protection Behavior. Paper under review. 2011a

Santiago Rivas M, Velicer WF, Redding CA, Prochaska JO, Paiva AL. Cluster Subtypes within the Contemplation Stage of Change for Sun Protection Behavior. Paper under review. 2011b

Stotts A, DiClemente CC, Carbonari JP, Mullen PD. Postpartum return to smoking: Staging a "suspended" behavior. Health Psychology. 2000; 19(4):324-332. [PubMed: 10907650]

Thyrian JR, Hannover W, Roske K, Rumpf HJ, John U, Hapke U. Postpartum return to smoking: Identifying different groups to tailor interventions. Addictive Behaviors. 2006; 31:1785-1796. [PubMed: 16431031]

Todd S, LaSala K, Neil-Urban S. An integrated approach to prenatal smoking cessation interventions. MCN, The American Journal of Maternal/Child Nursing. 2001; 26(4):185-190.

US Department of Health and Human Services. Tobacco Use. Vol. Chapter 27. 2000. Healthy People 2010: Objectives for Improving Health; p. 27-3-27-40.

US Department of Health and Human Services. How Tobacco Smoke Causes Disease: The Biology and Behavioral Basis for Smoking-Attributable Disease: A Report of the Surgeon General. Atlanta GA: U.S. Department of Health and Human Services, Centers for Disease Control and Prevention, National Center for Chronic Disease Prevention and Health Promotion, Office on Smoking and Health; 2010.

Velicer WF, Redding CA, Anatchkova MD, Fava JL, Prochaska JO. Identifying Cluster Subtypes for the Prevention of Adolescent Smoking Acquisition. Addictive Behaviors. 2007; 32:228-247. [PubMed: 16697533]

Velicer WF, Redding C, Paiva A, Burditt C, Harrington M, Meier K, Oatley K, Prochaska JO. Prevention Subgroups for Alcohol and Smoking: Replication across Samples and Behaviors. Psychology \& Health. 2009; 24:402. (Abstract).

Velicer WF, DiClemente CC, Prochaska JO, Brandenburg N. A decisional balance measure for assessing and predicting smoking status. Journal Personal and Social Psychology. 1985; 48:12791289.

Velicer WF, DiClemente CC, Rossi J, Prochaska J. Relapse situations and self-efficacy: An integrative model. Addictive Behaviors. 1990; 15:217-283.

Velicer WF, Hughes SL, Fava JL, Prochaska JO, DiClemente CC. An empirical typology of subjects within stage of change. Addictive Behaviors. 1995; 20:299-320. [PubMed: 7653313]

Velicer WF, Prochaska JO, Bellis JM, DiClemente CC, Rossi JS, Fava JL, et al. An expert system intervention for smoking cessation. Addictive Behaviors. 1993; 18:269-290. [PubMed: 8342440]

Velicer WF, Prochaska JO. An expert system intervention for smoking cessation. Patient Education and Counseling. 1999; 36:119-129. [PubMed: 10223017] 
Velicer WF, Prochaska JO, Fava JL, La Forge RG, Rossi JS. Interactive versus noninteractive interventions and dose-response relationships for stage-matched smoking cessation programs in a managed care setting. Health Pyschology. 1999; 18(1):21-28.

Velicer WF, Prochaska JO, Redding CA. Tailored communications for smoking cessation: Past successes and future directions. Drug and Alcohol Review. 2006; 25:47-55.

Velicer WF, Prochaska JO, Rossi JS, Snow M. Assessing outcome in smoking cessation studies. Psychological Bulletin. 1992; 111:23-41. [PubMed: 1539088]

Walsh RA, Redman S, Brinsmead MW, Byrne JM, Melmeth A. A smoking cessation program at a public antenatal clinic. American Journal of Public Health. 1997; 87(7):1201-1204. [PubMed: 9240113]

Woodby LL, Windsor RA, Snyder SW, Kohler CL, DiClemente CC. Predictors of smoking cessation during pregnancy. Addiction. 1999; 94(2):283-292. [PubMed: 10396795]

Ziebland S, Fuller A. Smoking cessation in pregnancy: What's a man to do? Health Education Journal. 2001; 60(3):232-40. 


\section{Highlights}

- This study focused on women who quit smoking either before or during pregnancy but then relapse during the postpartum period.

- A cluster analysis found four subgroups.

- The clusters were labeled Most Protected, Ambivalent, Risk Denial, and High Risk.

- The clusters and exclusive breastfeeding were the only significant predictors of relapse at 2-months postpartum.

- The results confirmed the clusters previously identified in prevention research with both adolescents and postpartum women. 


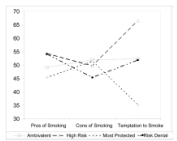

Figure 1.

4-Cluster solution for sample of 121 women who quit smoking for pregnancy and planned to remain nonsmokers postpartum. 
Table 1

Sociodemographic Characteristics of the Sample $(\mathrm{N}=144)$

\begin{tabular}{llc}
\hline & \multicolumn{2}{c}{ Sociodemographic Statistics } \\
\cline { 2 - 3 } & (Number) & Percent \\
\hline Education & & \\
< HS & $(19)$ & $13.2 \%$ \\
High cchool & $(36)$ & $25 \%$ \\
$\quad$ GED & $(13)$ & $9 \%$ \\
Diploma & $(23)$ & $16 \%$ \\
HS+ & $(79)$ & $54.86 \%$ \\
Some college & $(32)$ & $22.2 \%$ \\
College degree & $(47)$ & $32.6 \%$ \\
College+ & $(10)$ & $6.94 \%$ \\
Race & & \\
White & $(93)$ & $64.6 \%$ \\
Hispanic & $(21)$ & $14.6 \%$ \\
Asian & $(10)$ & $6.9 \%$ \\
Black/AA & $(10)$ & $6.9 \%$ \\
Other & $(9)$ & $6.3 \%$ \\
NA/PI & $(1)$ & $0.7 \%$ \\
Marital status & & $35 \%$ \\
Married & $(80)$ & $55.6 \%$ \\
Single & $(50)$ & $34.7 \%$ \\
Other & $(14)$ & $9.7 \%$ \\
Bnfant Feeding at Birth & & \\
Breastfeeding & $(53)$ & $54.2 \%$ \\
Bottle feeding & $(48)$ & \\
Yeth & $(43)$ & \\
No & & \\
\hline
\end{tabular}

Sociodemographic Statistics

\begin{tabular}{lccc}
\cline { 2 - 4 } & Mean $($ SD $)$ & Median & Range \\
\hline Age $(n=143)$ & $27.9(5.88)$ & 28 & $16-43$ \\
Income $(n=140)$ & $\$ 50,970(\$ 29,710)$ & $\$ 45,000$ & $<\$ 15,000->\$ 90,000$ \\
Number of pregnancies $(N=144)$ & $1.97(1.49)$ & 1 & $1-9$ \\
\hline
\end{tabular}




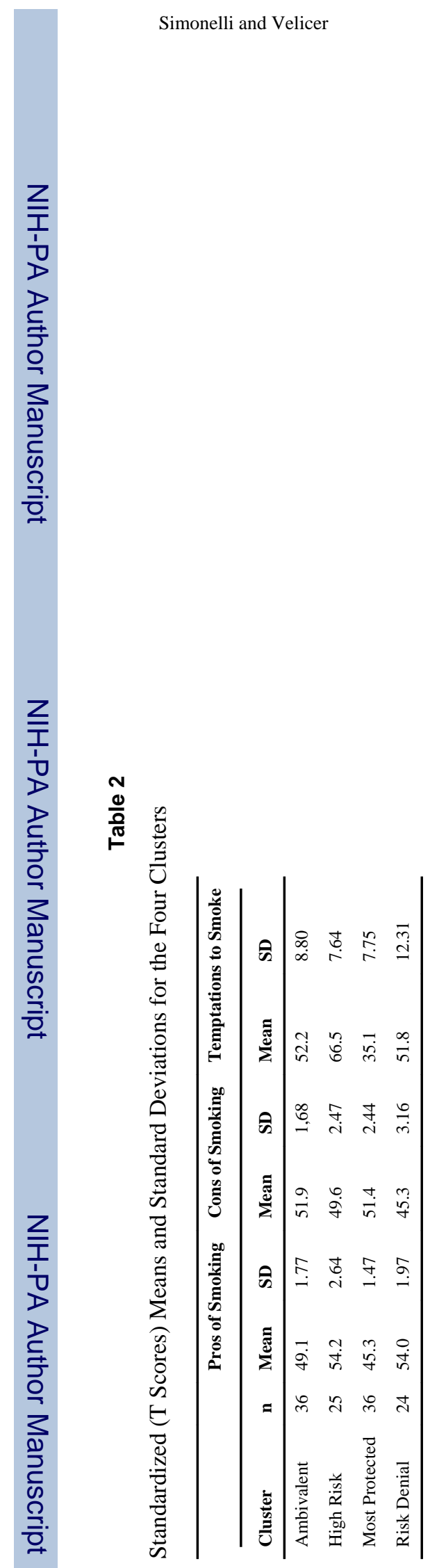

Addict Behav. Author manuscript; available in PMC 2013 March 1. 
Table 3

Variables to Predict Relapse to Smoking at 2 Months Postpartum ( $\mathrm{n}=113)$

\begin{tabular}{|c|c|c|c|c|}
\hline Variable & $\boldsymbol{B}$ & S.E. & Odds Ratio & $95.0 \%$ C.I. \\
\hline High Risk $^{* *}$ & 1.47 & .64 & 4.360 & $1.24-15.30$ \\
\hline Risk Denial $^{* *}$ & 1.26 & .65 & 3.539 & $1.00-12.52$ \\
\hline Ambivalent & .97 & .59 & 2.629 & $.83-8.38$ \\
\hline \multicolumn{5}{|l|}{ Protected $^{+}$} \\
\hline Age & -.01 & .04 & .986 & $.91-1.08$ \\
\hline \multicolumn{5}{|l|}{ Partner Smoker } \\
\hline Yes & .61 & .49 & 1.84 & $.71-4.77$ \\
\hline \multicolumn{5}{|l|}{$\mathrm{No}^{+}$} \\
\hline \multicolumn{5}{|l|}{ Education } \\
\hline$<12$ Years & 1.53 & .91 & 4.604 & $.77-27.38$ \\
\hline H. S. Grad & -.41 & .53 & .662 & $.24-1.85$ \\
\hline \multicolumn{5}{|l|}{$>12$ Years $^{+}$} \\
\hline \multicolumn{5}{|l|}{ Breast Only } \\
\hline $\begin{array}{l}\mathrm{Yes}^{* *} \\
\mathrm{No}^{+}\end{array}$ & \multicolumn{4}{|c|}{$\mathrm{No}^{+}$} \\
\hline \multicolumn{5}{|c|}{ Reference Category. } \\
\hline \multicolumn{5}{|c|}{$* *$} \\
\hline$* * * \quad p<.01$. & & & & \\
\hline
\end{tabular}

